\title{
Calidad del informe de resultados de la detección molecular de SARS-CoV-2: necesidad de estandarización
}

\author{
Quality of the SARS-CoV-2 molecular detection \\ report: the need for standardization
}

Eduardo Mucito-Varela*

\begin{abstract}
RESUMEN
El informe de resultados es un mecanismo de comunicación entre el laboratorio clínico y los médicos, por lo que su contenido debe ajustarse a los criterios de calidad internacionales. En el contexto de la pandemia por COVID-19, el diagnóstico molecular realizado en 163 laboratorios de México ha incrementado la capacidad diagnóstica y monitoreo epidemiológico. A pesar de contar con guías nacionales e internacionales para la interpretación de este examen, no se ha estandarizado el contenido del informe, lo que aumenta el riesgo de errores que afectan la seguridad del paciente. En este estudio se propone una lista de requisitos estandarizados basados en la Norma ISO 1589:2012, con la cual se evaluó el contenido de 13 informes de laboratorio. Se detectaron requisitos que deben ser mejorados y otros implementados, con el objetivo de garantizar el uso apropiado de la prueba de detección molecular del virus SARS-CoV-2, así como la correcta interpretación y el aseguramiento de la calidad postexamen de los laboratorios clínicos. Es necesario realizar un consenso más detallado en el que participen sociedades de profesionales del laboratorio clínico y médicos para generar un informe que agregue valor a la atención de los pacientes.
\end{abstract}

Palabras clave: Gestión de la calidad, laboratorio clínico, seguridad del paciente, estandarización, COVID-19.

\begin{abstract}
The laboratory report is a communication mechanism between the clinical laboratory and the physicians, so its content must comply with international quality criteria. In the context of the COVID-19 pandemic, the molecular diagnosis carried out in 163 laboratories in Mexico has increased the diagnostic capacity and epidemiological monitoring. Despite having national and international guidelines for the interpretation of this test, the content of the report has not been standardized, increasing the risk of errors that affect patient safety. This study proposes a list of standardized requirements based on the ISO 1589:2012 standard, which was used to evaluate the content of 13 laboratory reports. Some requirements should be improved and others implemented, in order to guarantee the appropriate use of the molecular detection of the SARS-CoV-2 virus, the correct interpretation and the quality assurance of the post-examination phase of the clinical laboratories. A more detailed consensus is needed where participation of societies of clinical laboratory professionals and physicians is needed to generate a report that adds value to patient care.
\end{abstract}

Keywords: Quality management, clinical laboratory, patient safety, standardization, COVID-19.
* Maestro en Ciencias, Químico Bacteriólogo Parasitólogo. Profesor de asignatura, Escuela de Ciencias de la Salud, Universidad del Valle de México campus Coyoacán. CDMX, México.

Correspondencia: EMV eduardomucito@gmail. com

Conflicto de intereses: Ninguno.

Citar como: Mucito-Varela

E. Calidad del informe de resultados de la detección molecular de SARS-CoV-2: necesidad de estandarización. Rev CONAMED. 2027; 26(1): 3-16. https://dx.doi. org/10.35366/99123

Financiamiento: Investigación financiada por el propio autor.

Recibido: 28/10/2020. Aceptado: 17/02/2021. 


\section{INTRODUCCIÓN}

Para que los resultados del laboratorio clínico sean confiables se debe implementar una serie de procesos que permitan controlar y garantizar su calidad, ya que al proporcionar un resultado incorrecto o a destiempo se incrementa la probabilidad de originar errores médicos que pueden ocasionar daños graves o irreparables al paciente.,2 El informe de resultados se realiza en la etapa postexamen, el cual requiere un proceso de validación, redacción y entrega de resultados. La interpretación y acción del médico acorde al resultado corresponden a la etapa postexamen clínica (post-postexamen). ${ }^{3}$ Dado que los errores en estas etapas extraanalíticas ocurren en frecuencias cercanas a $70 \%$, se han establecido indicadores de calidad para detectar errores y evaluar el desempeño de los procesos de estas etapas. ${ }^{4,5}$

Los errores más comunes reportados en la etapa postexamen son: tiempo de respuesta prolongado, resultados incorrectos, notificación tardía de resultados críticos y reportes extraviados. ${ }^{5}$ Se conoce poco sobre los errores en la etapa postexamen clínica, ya que muchas veces se considera que el laboratorio no tiene injerencia en ella al contemplar actividades fuera de sus instalaciones. ${ }^{4}$ Sin embargo, el laboratorio clínico puede impactar positivamente en esta etapa a través del aseguramiento de la calidad del informe, aportando la información necesaria y estructurada que permita al médico interpretarla de manera adecuada. ${ }^{6}$

La reacción en cadena de la polimerasa en tiempo real ha sido la herramienta diagnóstica de enfermedades virales como la influenza, el MERS y el SARS. En la pandemia actual de la enfermedad por coronavirus 2019 (COVID-19), es el método de elección para la confirmación de casos.7 En México, la Secretaría de Salud autorizó, hasta la fecha de escritura de este reporte, a 163 laboratorios del sector público y privado para el apoyo diagnóstico y monitoreo epidemiológico de la infección por SARS-CoV-2. ${ }^{8}$ Estos laboratorios tuvieron que pasar por un proceso de evaluación para homologar el criterio diagnóstico. Sin embargo, los requisitos del informe no están bien definidos y se asume que cumplen los criterios internacionales de calidad.

El objetivo de este estudio es identificar los requisitos del contenido del informe de resultados de la detección molecular de SARS-CoV-2 y comparar la calidad de los informes de laboratorios en México que realizan este examen, para proponer acciones de mejora que permitan garantizar la calidad postexamen y la seguridad del paciente.

\section{MATERIAL Y MÉTODOS}

\section{Identificación de requisitos del informe de resultados}

Se identificaron los requisitos del informe de resultados en la Norma 15189:2012 de la Organización Internacional para la Estandarización (ISO). Adicionalmente, se identificaron requisitos en la NOM-007-SSA3-2011, ${ }^{9}$ en las recomendaciones postanalíticas de la Sociedad Croata de Bioquímica Médica y Medicina de Laboratorio (CSMBLM), ${ }^{10}$ en las guías para el diagnóstico molecular de SARSCoV-2 publicadas por la Sociedad Coreana de Medicina de Laboratorio-Centro para la Prevención de Enfermedades de Corea (KSLM-KCDC)" y por la Federación Internacional de Bioquímica Clínica y Medicina de Laboratorio (IFCC). ${ }^{12}$

\section{Evaluación del contenido del informe de resultados}

Se evaluaron los informes de resultados de pacientes que voluntariamente aceptaron mostrar su informe, y se utilizaron los requisitos identificados como referencia. Sólo se evaluó un formulario por laboratorio cuando se presentó más de un paciente que haya acudido al mismo laboratorio. La información personal sensible de los pacientes y de los laboratorios cuyos informes fueron analizados no se incluyó en los registros de datos. Esta información sólo se utilizó con fines de identificación única y se codificó para los registros de la investigación.

Después de completar la evaluación con la lista de verificación, se calculó el grado de cumplimiento de cada requisito por laboratorio, expresado como porcentaje del número de elementos contenidos sobre el total de elementos de cada requisito (grado de cumplimiento del requisito (\%) = número de elementos contenidos/total de elementos requisitados * 100). Los elementos que se consideraron que no aplican a un grupo de laboratorios en particular, no se contemplaron para el cálculo 
del porcentaje del cumplimiento del requisito. Por último, se calculó un porcentaje de cumplimento global sumando los porcentajes de todos los requisitos por laboratorio. Esta estimación se estratificó en: 1) sector público, incluyendo laboratorios de la Secretaría de Salud y de la Academia, y 2) sector privado, todos los laboratorios que funcionan como organizaciones particulares no ligadas a los servicios de salud que proporciona el Estado.

Para el análisis de palabras se utilizó la aplicación web ToCloud (disponible en http://www. tocloud.com/). El conteo de artículos y preposiciones como palabras individuales se excluyó de los resultados finales.

\section{RESULTADOS}

\section{Requisitos del informe de resultados}

Se establecieron 15 requisitos generales y 36 elementos para cubrirlos (Tabla 7). La Norma ISO 15189 establece 16 requisitos para el informe en su sección 5.8.3, de los cuales los requisitos fy g fueron considerados como uno solo en esta propuesta ( $f y$ g, información de muestra primaria). Los elementos específicos para cubrir algunos requisitos de la ISO 15189 no se definen con exactitud, lo cual permite la adecuación de los elementos para cada laboratorio. En las recomendaciones de la CSMBLM se identificaron cinco requisitos y 30 elementos para cubrirlos. En las guías de la KSLM-KCDC para el diagnóstico de COVID-19 se consideraron cuatro requisitos para el informe, para los cuales se sugieren algunos elementos a contener en tres de los requisitos. En la NOM-007-SSA3-2011 se reconocieron tres elementos (nombre, firma y cédula) para cubrir el requisito de identificación del responsable de laboratorio y liberación del informe. En la guía de la IFCC para el diagnóstico molecular de SARSCoV-2 no se establecen requisitos específicos para el informe; sin embargo, las recomendaciones para la validación e interpretación fueron consideradas como elementos de los comentarios.

\section{Evaluación del contenido del informe de resultados}

Se analizaron 13 informes de laboratorio, 12 de ellos representan cerca de 8\% (12 de 159) del total de laboratorios autorizados por la Secretaría de Salud para el apoyo en el diagnóstico de COVID-19, mientras que un laboratorio subcontrató a un laboratorio autorizado por la Secretaría de Salud. Ocho de los informes analizados correspondieron a laboratorios del sector privado y cinco al sector público (cuatro laboratorios del Sistema Nacional de Salud, un laboratorio de la Academia).

En general, los laboratorios del sector privado tuvieron promedios mayores de cumplimiento de los requisitos a nivel individual (promedio 63.5 vs 44.7\%). El mayor porcentaje de cumplimiento global por laboratorio fue de $72.5 \%$ mientras que el menor fue de $29.1 \%$, correspondiente a un laboratorio privado y público, respectivamente.

Los requisitos de «identificación del examen» e «identificación del laboratorio emisor» tuvieron los promedios de cumplimiento más altos, con puntajes de 100 y 96.2\%, respectivamente; la «interpretación de resultados» de 92.3\%; el «intervalo de referencia» de 76.9\%; la «identificación de responsable de revisión y autorización del informe» de $75 \%$. El resto de los requisitos tuvo un promedio menor a 70\%, siendo «la unidad de resultados» el requisito que presentó $0 \%$ en el cumplimiento. El porcentaje de cumplimiento de los requisitos del informe se muestra en la Tabla 2. A continuación se muestran detalles del contenido de algunos requisitos:

\section{Identificación del examen y el laboratorio (a-c)}

De los informes analizados 13/13 contienen los elementos para cubrir al requisito «a». Los nombres del examen y del procedimiento utilizado son heterogéneos. Para el nombre del examen las palabras más frecuentes utilizadas fueron: "SARS-CoV-2», «detección», «COVID-19»y «coronavirus».

La palabra «RT-PCR» fue la más empleada en el nombre del procedimiento del examen, apareciendo en 8/13 de los informes, pero sólo cinco utilizaron los nombres sin abreviar. En 2/13 no se encontró un apartado o frase independiente que definiera esta sección. La dirección del laboratorio emisor no se mostró en 1/13 reportes, y un laboratorio que usó servicios subcontratados no identificó al laboratorio. 
Tabla 1: Propuesta de contenido estandarizado para el informe de resultados de la detección molecular de SARS-CoV-2.

Requisito de acuerdo

a ISO 15189

Elemento a contener

Contenido estandarizado

a) Identificación del examen

b) Identificación del laboratorio emisor

c) Identificación de exámenes subcontratados

d) Identificación del paciente
1. Nombre del examen',"II Nombre sugerido: «Detección cualitativa (Debe reflejar el objetivo o lo que se pretende medir)

2. Nombre del procedimientol (Debe especificar las herramientas o técnicas que se emplean para lograr el objetivo)

3. Nombre del laboratorio"lI

4. Dirección del laboratorio"II

5. Señalamiento del examen subcontratadov

6. Identificación del laboratorio subcontratado ${ }^{\text {vi }}$

7. Nombre del paciente $,||,,|$,

8. Número único de identificación ${ }^{|,|,|l|}$

9. Fecha de nacimiento ${ }^{\|,\| 11}$

10. Edad"

11. $\operatorname{SexO} 0^{11,111}$

12. Ubicación!,II del coronavirus SARS-CoV-2»

Nombre sugerido: «Retrotranscripción y amplificación por reacción en cadena de la polimerasa con detección de sondas fluorescentes»

Opcional: colocar las siglas entre paréntesis «(RT-

qP(R)» después del nombre completo

Opcional: el nombre del procedimiento puede ir seguido del nombre y la marca del kit de amplificación

Razón social del laboratorio

Dirección, teléfono y/o fax, correo

electrónico, página web (opcional)

Colocar una acotación delante del nombre del examen subcontratado

Especificar el nombre y dirección del laboratorio que maquila el examen subcontratado haciendo referencia a la acotación indicada del punto anterior

La ubicación puede ser en una nota al pie de página o inmediatamente después de la sección de identificación del examen

Nombre(s), apellido paterno y apellido materno separados por espacios

Se puede usar alguno de los siguientes elementos: folio único, número de orden, número de expediente Especificar con números el día, mes y año de nacimiento

Especificar el número de años cumplidos seguido de la palabra «años»

Especificar sexo biológico: masculino, femenino o intersexual

Con fines de inclusión se puede colocar una nota con la identidad de género del paciente en caso de que el paciente no se identifique con su sexo biológico Para laboratorios públicos, especificar unidad o número de clínica en la que se tomó muestra al paciente

Cuando el paciente solicita por su cuenta, escribir el domicilio del paciente 


\section{Continúa Tabla 1: Propuesta de contenido estandarizado para el informe} de resultados de la detección molecular de SARS-CoV-2.

\begin{tabular}{|c|c|c|c|}
\hline & $\begin{array}{l}\text { Requisito de acuerdo } \\
\text { a ISO } 15189\end{array}$ & Elemento a contener & Contenido estandarizado \\
\hline & & $\begin{array}{l}\text { 13. Datos del paciente en } \\
\text { todas las páginas, III }\end{array}$ & $\begin{array}{l}\text { Debe contener todos los datos de identificación } \\
\text { del paciente en todas las páginas del informe }\end{array}$ \\
\hline \multirow[t]{3}{*}{ e) } & $\begin{array}{l}\text { Identificación } \\
\text { del solicitante }\end{array}$ & $\begin{array}{l}\text { 14. Nombre del médico } \\
\text { solicitante, }, \text {,IIII }\end{array}$ & Nombre(s) y apellido(s) del médico solicitante \\
\hline & & $\begin{array}{l}\text { 15. Solicitud del paciente } \\
\text { sin orden médicavl }\end{array}$ & $\begin{array}{l}\text { En caso de que el paciente solicite la prueba sin orden } \\
\text { médica, debe contener nota o mención que así lo } \\
\text { determine. Ej. «Solicitud por voluntad del paciente» }\end{array}$ \\
\hline & & $\begin{array}{l}\text { 16. Información de } \\
\text { contacto del } \\
\text { solicitante }\end{array}$ & $\begin{array}{l}\text { Debe contener datos de contacto como } \\
\text { teléfono y/o correo electrónico }\end{array}$ \\
\hline \multirow{3}{*}{\multicolumn{2}{|c|}{$\begin{array}{l}\text { fy g) Información de } \\
\text { muestra primaria }\end{array}$}} & $\begin{array}{l}\text { 17. Tipo de muestra } \\
\text { primaria,,I,III }\end{array}$ & $\begin{array}{l}\text { Especificar el tipo de muestra primaria: exudado } \\
\text { nasofaríngeo, exudado faríngeo, saliva }\end{array}$ \\
\hline & & $\begin{array}{l}\text { 18. Fecha de la toma } \\
\text { de la muestra, }, \text {,IIII }\end{array}$ & Especificar día, mes y año de la toma de la muestra \\
\hline & & $\begin{array}{l}\text { 19. Hora de la toma } \\
\text { de la muestra,,I,III }\end{array}$ & $\begin{array}{l}\text { Especificar la hora de la toma de la muestra. } \\
\text { Formato sugerido en horas:minutos:segundos }\end{array}$ \\
\hline \multirow[t]{5}{*}{ h) } & $\begin{array}{l}\text { Procedimiento } \\
\text { de medición }\end{array}$ & $\begin{array}{l}\text { 20. Nombre de } \\
\text { los blancos } \\
\text { moleculares }{ }^{1 *}\end{array}$ & $\begin{array}{l}\text { Especifica el nombre de los blancos } \\
\text { moleculares (genes) de la prueba }\end{array}$ \\
\hline & & $\begin{array}{l}\text { 21. Valor de corte de } \\
\text { ciclo umbral (Ct) } \\
\text { de cada gen }{ }^{\prime \prime, *}\end{array}$ & $\begin{array}{l}\text { Especifica un valor de ciclo umbral que delimita } \\
\text { la capacidad de detección de la prueba }\end{array}$ \\
\hline & & $\begin{array}{l}\text { 22. Criterio de } \\
\text { determinación }\end{array}$ & $\begin{array}{l}\text { Especifica los criterios de determinación } \\
\text { del resultado de la muestra }\end{array}$ \\
\hline & & $\begin{array}{l}\text { de positividad y } \\
\text { negatividad"** }\end{array}$ & $\begin{array}{l}\text { Positivo: valor de ciclo umbral (Ct) de la muestra menor } \\
\text { que el valor de corte del ciclo umbral del gen }\end{array}$ \\
\hline & & & $\begin{array}{l}\text { Negativo: no amplificación o valor de ciclo umbral (Ct) de la } \\
\text { muestra mayor que el valor de corte del ciclo umbral del gen }\end{array}$ \\
\hline i) & $\begin{array}{l}\text { Unidades del } \\
\text { resultado }\end{array}$ & $\begin{array}{l}\text { 23. Expresa valor de ciclo } \\
\text { umbral (Ct) como } \\
\text { unidad de medición }{ }^{v 1}\end{array}$ & $\begin{array}{l}\text { Especifica un valor de ciclo umbral (Ct) para la amplificación } \\
\text { de cada gen amplificado en la muestra del paciente }\end{array}$ \\
\hline j) & $\begin{array}{l}\text { Intervalo de } \\
\text { referencia }\end{array}$ & $\begin{array}{l}\text { 24. Valor esperado de } \\
\text { cada gen empleado" }\end{array}$ & $\begin{array}{l}\text { Especifica el resultado esperado de cada gen } \\
\text { empleado como Negativo o No amplificado }\end{array}$ \\
\hline k) & $\begin{array}{l}\text { Interpretación } \\
\text { del resultado }\end{array}$ & $\begin{array}{l}\text { 25. Explicación de } \\
\text { los resultados de } \\
\text { amplificación }\end{array}$ & $\begin{array}{l}\text { Explica en una oración la presencia o ausencia del } \\
\text { virus SARS-CoV-2 en la muestra, de acuerdo con la } \\
\text { combinación de blancos moleculares empleados }\end{array}$ \\
\hline \multirow[t]{2}{*}{ 1) } & Comentarios & $\begin{array}{l}\text { 26. Utilidad del } \\
\text { examen }{ }^{\|*,\| l, v *}\end{array}$ & $\begin{array}{l}\text { Explicación sobre la sensibilidad diagnóstica } \\
\text { del método y la necesidad de complementarlo } \\
\text { con los datos clínicos y epidemiológicos }\end{array}$ \\
\hline & & & $\begin{array}{l}\text { Información de calidad o conformidad } \\
\text { sobre la muestra primaria }\end{array}$ \\
\hline
\end{tabular}




\section{Continúa Tabla 1: Propuesta de contenido estandarizado para el informe} de resultados de la detección molecular de SARS-CoV-2.

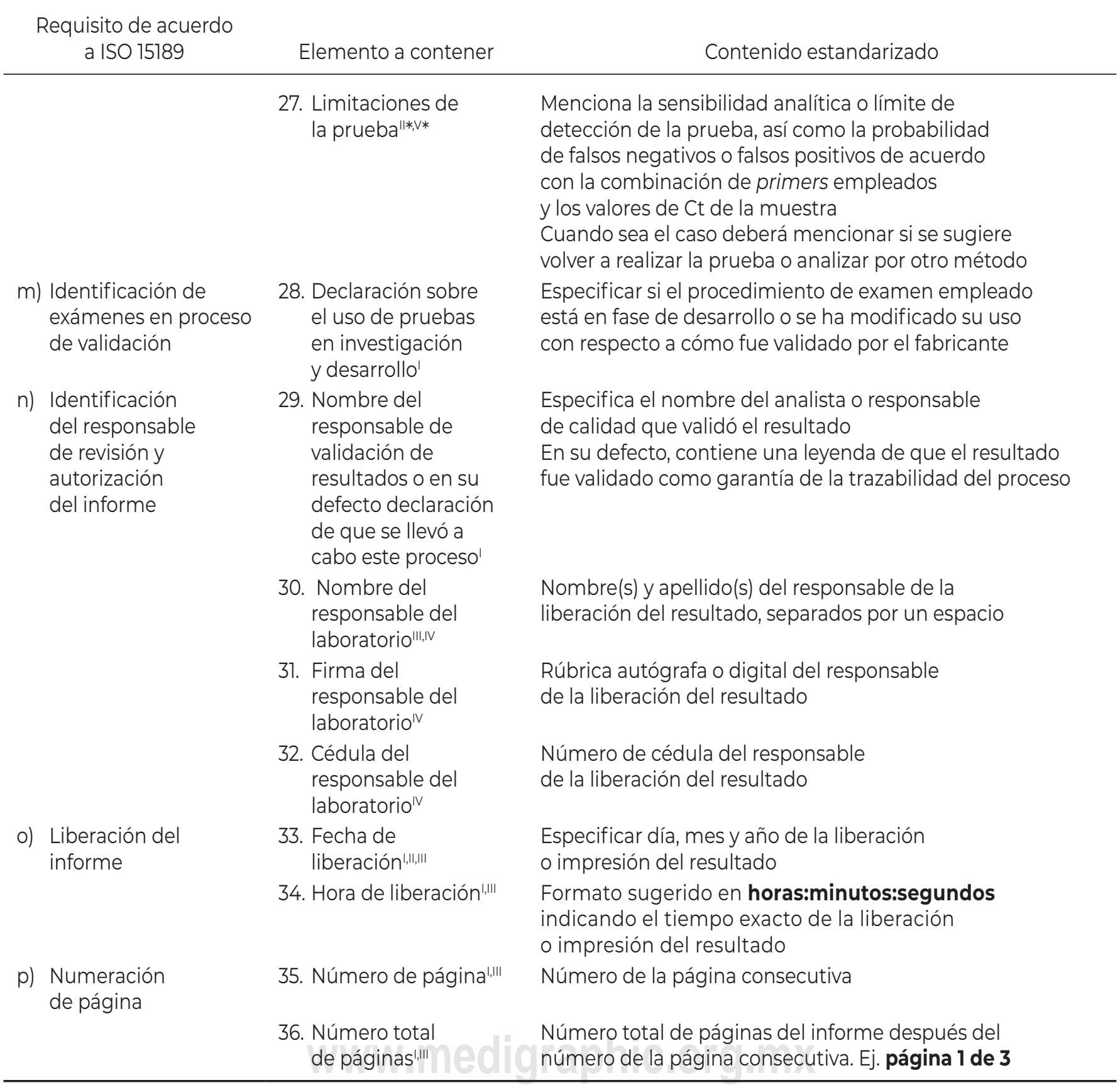

\footnotetext{
' Elemento de acuerdo con recomendación de ISO 15189

"Elemento de acuerdo con recomendación de KSLM-KCDC."

"II Elemento de acuerdo con recomendación de CSMBLM.10

Iv Elemento de acuerdo con recomendación de NOM-007-SSA3-2011. ${ }^{9}$

$\checkmark$ Elemento de acuerdo con recomendación de IFCC. ${ }^{12}$

vi Elemento propuesto por el autor de acuerdo con la revisión de la literatura. ${ }^{19,20}$

* Elemento basado en recomendaciones para la interpretación de resultados.
} 
Tabla 2: Evaluación del informe de 13 laboratorios que realizan diagnóstico molecular de SARS-CoV-2 en México.

\begin{tabular}{|c|c|c|c|c|c|c|c|c|c|c|c|c|c|c|c|c|c|}
\hline \multirow[b]{2}{*}{$\begin{array}{l}\text { Requisito de } \\
\text { acuerdo a } \\
\text { ISO } 15189\end{array}$} & \multirow[b]{2}{*}{$\begin{array}{l}\text { Elemento de } \\
\text { contenido }\end{array}$} & \multicolumn{6}{|c|}{ Laboratorios públicos } & \multicolumn{9}{|c|}{ Laboratorios privados } & \multirow[b]{2}{*}{$\begin{array}{c}\text { Todos los } \\
\text { laboratorios } \\
\text { (promedio) }\end{array}$} \\
\hline & & 001 & 003 & 007 & 012 & 014 & $\begin{array}{l}\text { Total } \\
\text { por } \\
\text { sector }\end{array}$ & 002 & 004 & 005 & 008 & 009 & 010 & 011 & 013 & $\begin{array}{l}\text { Total } \\
\text { por } \\
\text { sector }\end{array}$ & \\
\hline \multirow[t]{3}{*}{$\begin{array}{l}\text { a) Identificación } \\
\text { del examen }\end{array}$} & $\begin{array}{l}\text { 1. Nombre del } \\
\text { examen }\end{array}$ & Sí & Sí & Sí & Sí & Sí & $5 / 5$ & Sí & Sí & Sí & Sí & Sí & Sí & Sí & Sí & $8 / 8$ & $13 / 13$ \\
\hline & $\begin{array}{l}\text { 2. Nombre del } \\
\text { procedimiento }\end{array}$ & Sí & Sí & Sí & Sí & Sí & $5 / 5$ & Sí & Sí & Sí & Sí & Sí & Sí & Sí & Sí & $8 / 8$ & $13 / 13$ \\
\hline & $\%$ de cumplimiento & 100 & 100 & 100 & 100 & 100 & 100 & 100 & 100 & 100 & 100 & 100 & 100 & 100 & 100 & 100 & (100) \\
\hline \multirow{3}{*}{$\begin{array}{l}\text { b) Identificación } \\
\text { del laboratorio } \\
\text { emisor }\end{array}$} & $\begin{array}{l}\text { 3. Nombre del } \\
\text { laboratorio }\end{array}$ & Sí & Sí & Sí & Sí & Sí & $5 / 5$ & Sí & Sí & Sí & Sí & Sí & Sí & Sí & Sí & $8 / 8$ & $13 / 13$ \\
\hline & $\begin{array}{l}\text { 4. Dirección del } \\
\text { laboratorio }\end{array}$ & Sí & Sí & Sí & Sí & No & $4 / 5$ & Sí & Sí & Sí & Sí & Sí & Sí & Sí & Sí & $8 / 8$ & $12 / 13$ \\
\hline & $\begin{array}{l}\% \text { de cumplimiento } \\
\text { por laboratorio }\end{array}$ & 100 & 100 & 100 & 100 & 50 & 90 & 100 & 100 & 100 & 100 & 100 & 100 & 100 & 100 & 100 & (96.15) \\
\hline \multirow[t]{3}{*}{$\begin{array}{l}\text { c) Identificación } \\
\text { de exámenes } \\
\text { referenciados* }\end{array}$} & $\begin{array}{l}\text { 5. Señalamiento } \\
\text { del examen } \\
\text { subcontratado }\end{array}$ & NA & NA & NA & NA & NA & NA & NA & Sí & NA & NA & NA & NA & NA & NA & $1 / 1$ & $1 / 1$ \\
\hline & $\begin{array}{l}\text { 6. Identificación } \\
\text { del laboratorio } \\
\text { subcontratado }\end{array}$ & NA & NA & NA & NA & NA & NA & NA & No & NA & NA & NA & NA & NA & NA & $0 / 1$ & 0/1 \\
\hline & $\%$ de cumplimiento & NA & NA & NA & NA & NA & NA & NA & 50 & NA & NA & NA & NA & NA & NA & $50^{*}$ & $50 *$ \\
\hline \multirow[t]{8}{*}{$\begin{array}{l}\text { d) Identificación } \\
\text { del paciente }\end{array}$} & $\begin{array}{l}\text { 7. Nombre del } \\
\text { paciente }\end{array}$ & Sí & Sí & Sí & Sí & Sí & $5 / 5$ & Sí & Sí & Sí & Sí & Sí & Sí & Sí & Sí & $8 / 8$ & 13/13 \\
\hline & $\begin{array}{l}\text { 8. Número único de } \\
\text { identificación }\end{array}$ & Sí & Sí & Sí & Sí & No & $4 / 5$ & Sí & Sí & Sí & Sí & Sí & Sí & Sí & Sí & $8 / 8$ & $12 / 13$ \\
\hline & $\begin{array}{l}\text { 9. Fecha de } \\
\text { nacimiento }\end{array}$ & No & No & No & No & No & $0 / 5$ & No & Sí & No & No & No & Sí & No & No & $2 / 8$ & $2 / 13$ \\
\hline & 10. Edad & No & No & Sí & Sí & No & $3 / 5$ & Sí & Sí & Sí & No & Sí & Sí & Sí & Sí & $7 / 8$ & 10/13 \\
\hline & 11. Sexo & No & No & No & Sí & No & $4 / 5$ & Sí & Sí & No & No & Sí & Sí & Sí & Sí & $6 / 8$ & 10/13 \\
\hline & $\begin{array}{l}\text { 12. Ubicación del } \\
\text { paciente }\end{array}$ & Sí & No & Sí & No & No & $2 / 5$ & No & No & No & No & No & No & No & No & $8 / 8$ & 10/13 \\
\hline & $\begin{array}{l}\text { 13. Datos del paciente } \\
\text { en todas las páginas }\end{array}$ & Sí & Sí & Sí & Sí & Sí & $5 / 5$ & Sí & Sí & Sí & Sí & Sí & Sí & Sí & Sí & $8 / 8$ & $13 / 13$ \\
\hline & $\%$ de cumplimiento & 57.1 & 42.9 & 71.4 & 71.4 & 28.6 & 54.3 & 71.4 & 85.7 & 57.1 & 42.9 & 71.42 & 85.7 & 71.4 & 71.4 & 69.6 & (63.7) \\
\hline
\end{tabular}


Continúa Tabla 2: Evaluación del informe de 13 laboratorios que realizan diagnóstico molecular de SARS-CoV-2 en México.

\begin{tabular}{|c|c|c|c|c|c|c|c|c|c|c|c|c|c|c|c|c|c|}
\hline \multirow[b]{2}{*}{$\begin{array}{l}\text { Requisito de } \\
\text { acuerdo a } \\
\text { ISO } 15189\end{array}$} & \multirow[b]{2}{*}{$\begin{array}{l}\text { Elemento de } \\
\text { contenido }\end{array}$} & \multicolumn{6}{|c|}{ Laboratorios públicos } & \multicolumn{9}{|c|}{ Laboratorios privados } & \multirow[b]{2}{*}{$\begin{array}{c}\text { Todos los } \\
\text { laboratorios } \\
\text { (promedio) }\end{array}$} \\
\hline & & 001 & 003 & 007 & 012 & 014 & $\begin{array}{l}\text { Total } \\
\text { por } \\
\text { sector }\end{array}$ & 002 & 004 & 005 & 008 & 009 & 010 & 011 & 013 & $\begin{array}{l}\text { Total } \\
\text { por } \\
\text { sector }\end{array}$ & \\
\hline \multirow[t]{4}{*}{$\begin{array}{l}\text { e) Identificación } \\
\text { del solicitante }\end{array}$} & $\begin{array}{l}\text { 14. Nombre } \\
\text { del médico } \\
\text { solicitante }\end{array}$ & No & No & Sí & No & No & $1 / 5$ & No & Sí & No & No & No & No & Sí & No & $2 / 8$ & $3 / 13$ \\
\hline & $\begin{array}{l}\text { 15. Menciona si el } \\
\text { paciente solicita } \\
\text { por su voluntad }\end{array}$ & No & No & NA & No & No & $0 / 4$ & No & NA & No & No & No & No & NA & No & $0 / 6$ & $0 / 13$ \\
\hline & $\begin{array}{l}\text { 16. Información de } \\
\text { contacto del } \\
\text { solicitante }\end{array}$ & No & No & No & No & No & $0 / 5$ & No & No & No & No & No & No & No & No & $0 / 8$ & $0 / 13$ \\
\hline & $\%$ de cumplimiento & 0 & 0 & 50 & 0 & 0 & 10 & 0 & 50 & 0 & 0 & 0 & 0 & 50 & 0 & 12.5 & (11.5) \\
\hline \multirow{4}{*}{$\begin{array}{l}\text { fy g) Información } \\
\text { de muestra } \\
\text { primaria }\end{array}$} & $\begin{array}{l}\text { 17. Tipo de muestra } \\
\text { primaria }\end{array}$ & Sí & Sí & Sí & Sí & No & $4 / 5$ & Sí & No & Sí & Sí & Sí & Sí & Sí & Sí & $7 / 8$ & 11/13 \\
\hline & $\begin{array}{l}\text { 18. Fecha de toma } \\
\text { de muestra }\end{array}$ & Sí & Sí & No & Sí & No & $3 / 5$ & No & Sí & Sí & No & Sí & Sí & Sí & Sí & $6 / 8$ & $9 / 13$ \\
\hline & $\begin{array}{l}\text { 19. Hora de toma } \\
\text { de muestra }\end{array}$ & No & No & No & No & No & $0 / 5$ & No & No & No & No & Sí & Sí & No & Sí & $3 / 8$ & $3 / 13$ \\
\hline & $\%$ de cumplimiento & 66.7 & 66.7 & 33.3 & 66.7 & 0 & 46.7 & 33.3 & 33.3 & 66.7 & 33.3 & 100 & 100 & 66.7 & 100 & 66.7 & (59) \\
\hline \multirow{4}{*}{$\begin{array}{l}\text { h) Procedimiento } \\
\text { de medición }\end{array}$} & $\begin{array}{l}\text { 20. Nombre de } \\
\text { los blancos } \\
\text { moleculares }\end{array}$ & No & No & No* & No & No & $0 / 5$ & No & No & Sí & Sí & No & No* & No & Sí & $3 / 5$ & $3 / 13$ \\
\hline & $\begin{array}{l}\text { 21. Valor de corte } \\
\text { de Ct de } \\
\text { cada blanco } \\
\text { molecular }\end{array}$ & No & No & No & No & No & $0 / 5$ & No & No & No & No & No & No & No & No & $0 / 8$ & $0 / 13$ \\
\hline & $\begin{array}{l}\text { 22. Criterio de } \\
\text { determinación } \\
\text { de positividad }\end{array}$ & No & No & No & No & No & $0 / 5$ & No & No & No & No & No & No & No & No & $0 / 8$ & $0 / 13$ \\
\hline & $\%$ de cumplimiento & 0 & 0 & 0 & 0 & 0 & 0 & 0 & 0 & 33.3 & 33.3 & 0 & 0 & 0 & 33.3 & 12.5 & (7.7) \\
\hline $\begin{array}{l}\text { i) Unidades del } \\
\text { resultado }\end{array}$ & $\begin{array}{l}\text { 23. Expresa valor de } \\
\text { Ct como unidad } \\
\text { de medición }\end{array}$ & No & No & No & No & No & $0 / 5$ & No & No & No & No & No & No & No & No & $0 / 8$ & $0 / 13$ \\
\hline & $\%$ de cumplimiento & 0 & 0 & 0 & 0 & 0 & 0 & 0 & 0 & 0 & 0 & 0 & 0 & 0 & 0 & 0 & 0 \\
\hline
\end{tabular}


Continúa Tabla 2: Evaluación del informe de 13 laboratorios que realizan diagnóstico molecular de SARS-CoV-2 en México.

\begin{tabular}{|c|c|c|c|c|c|c|c|c|c|c|c|c|c|c|c|c|c|c|}
\hline \multirow{2}{*}{\multicolumn{2}{|c|}{$\begin{array}{l}\text { Requisito de } \\
\text { acuerdo a } \\
\text { ISO } 15189\end{array}$}} & \multirow[b]{2}{*}{$\begin{array}{l}\text { Elemento de } \\
\text { contenido }\end{array}$} & \multicolumn{6}{|c|}{ Laboratorios públicos } & \multicolumn{9}{|c|}{ Laboratorios privados } & \multirow[b]{2}{*}{$\begin{array}{c}\text { Todos los } \\
\text { laboratorios } \\
\text { (promedio) }\end{array}$} \\
\hline & & & 001 & 003 & 007 & 012 & 014 & $\begin{array}{l}\text { Total } \\
\text { por } \\
\text { sector }\end{array}$ & 002 & 004 & 005 & 008 & 009 & 010 & 011 & 013 & $\begin{array}{l}\text { Total } \\
\text { por } \\
\text { sector }\end{array}$ & \\
\hline \multirow[t]{2}{*}{ j) } & $\begin{array}{l}\text { Intervalo de } \\
\text { referencia }\end{array}$ & $\begin{array}{l}\text { 24. Valor esperado } \\
\text { de cada gen } \\
\text { empleado*** }\end{array}$ & No & Sí & No & Sí & No & $2 / 5$ & Sí & Sí & Sí & Sí & Sí & Sí & Sí & Sí & $8 / 8$ & $10 / 13$ \\
\hline & & $\%$ de cumplimiento & 0 & 100 & 0 & 100 & 0 & 40 & 100 & 100 & 100 & 100 & 100 & 100 & 100 & 100 & 100 & (76.9) \\
\hline \multirow[t]{2}{*}{ k) } & $\begin{array}{l}\text { Interpretación } \\
\text { del resultado }\end{array}$ & $\begin{array}{l}\text { 25. Explicación de } \\
\text { los resultados de } \\
\text { amplificación }\end{array}$ & No & Sí & Sí & Sí & Sí & $4 / 5$ & Sí & Sí & Sí & Sí & Sí & Sí & Sí & Sí & $8 / 5$ & $12 / 13$ \\
\hline & & $\%$ de cumplimiento & 0 & 100 & 100 & 100 & 100 & 80 & 100 & 100 & 100 & 100 & 100 & 100 & 100 & 100 & 100 & $(92.3)$ \\
\hline \multirow[t]{3}{*}{ I) } & Comentarios & $\begin{array}{l}\text { 26. Utilidad del } \\
\text { examen }\end{array}$ & Sí & No & No & No & No & $1 / 5$ & No & No & No & No & Sí & No & Sí & Sí & $3 / 8$ & 4/13 \\
\hline & & $\begin{array}{l}\text { 27. Limitaciones } \\
\text { de la prueba }\end{array}$ & No & No & No & No & No & $0 / 5$ & No & No & No & No & No & No & No & Sí & $1 / 8$ & $1 / 13$ \\
\hline & & $\%$ de cumplimiento & 50 & 0 & 0 & 0 & 0 & 10 & 0 & 0 & 0 & 0 & 50 & 0 & 50 & 100 & 25 & (19.2) \\
\hline & $\begin{array}{l}\text { Identificación } \\
\text { de exámenes } \\
\text { en proceso } \\
\text { de validación }\end{array}$ & $\begin{array}{l}\text { 28. Declaración sobre } \\
\text { el uso de pruebas } \\
\text { en investigación } \\
\text { y desarrollo }\end{array}$ & NA & NA & NA & NA & NA & NA & NA & NA & NA & NA & NA & NA & NA & NA & NA & NA \\
\hline \multirow[t]{3}{*}{ n) } & $\begin{array}{l}\text { Identificación } \\
\text { del } \\
\text { responsable } \\
\text { de revisión y } \\
\text { autorización } \\
\text { del informe }\end{array}$ & $\begin{array}{l}\text { 29. Nombre del } \\
\text { responsable de } \\
\text { validación de } \\
\text { resultados o } \\
\text { en su defecto } \\
\text { declaración de } \\
\text { que se llevó } \\
\text { a cabo este } \\
\text { proceso }\end{array}$ & No & No & No & No & No & $0 / 5$ & No & Sí & No & Sí & No & Sí & Sí & No & $4 / 8$ & $4 / 13$ \\
\hline & & $\begin{array}{l}\text { 30. Nombre del } \\
\text { responsable del } \\
\text { laboratorio }\end{array}$ & Sí & Sí & Sí & Sí & Sí & $5 / 5$ & Sí & Sí & Sí & Sí & Sí & Sí & Sí & Sí & $8 / 8$ & $13 / 13$ \\
\hline & & $\begin{array}{l}\text { 31. Firma del } \\
\text { responsable del } \\
\text { laboratorio }\end{array}$ & Sí & Sí & Sí & Sí & Sí & $5 / 5$ & Sí & Sí & Sí & Sí & Sí & Sí & Sí & Sí & $8 / 8$ & $13 / 13$ \\
\hline
\end{tabular}


Continúa Tabla 2: Evaluación del informe de 13 laboratorios que realizan diagnóstico molecular de SARS-CoV-2 en México.

\begin{tabular}{|c|c|c|c|c|c|c|c|c|c|c|c|c|c|c|c|c|c|}
\hline \multirow[b]{2}{*}{$\begin{array}{l}\text { Requisito de } \\
\text { acuerdo a } \\
\text { ISO } 15189\end{array}$} & \multirow[b]{2}{*}{$\begin{array}{l}\text { Elemento de } \\
\text { contenido }\end{array}$} & \multicolumn{6}{|c|}{ Laboratorios públicos } & \multicolumn{9}{|c|}{ Laboratorios privados } & \multirow[b]{2}{*}{$\begin{array}{c}\text { Todos los } \\
\text { laboratorios } \\
\text { (promedio) }\end{array}$} \\
\hline & & 001 & 003 & 007 & 012 & 014 & $\begin{array}{l}\text { Total } \\
\text { por } \\
\text { sector }\end{array}$ & 002 & 004 & 005 & 008 & 009 & 010 & 011 & 013 & $\begin{array}{l}\text { Total } \\
\text { por } \\
\text { sector }\end{array}$ & \\
\hline & $\begin{array}{l}\text { 32. Cédula del } \\
\text { responsable del } \\
\text { laboratorio }\end{array}$ & No & No & Sí & Sí & No & $3 / 5$ & Sí & Sí & No & Sí & Sí & Sí & Sí & Sí & $7 / 8$ & 10/13 \\
\hline & $\%$ de cumplimiento & 50 & 50 & 75 & 75 & 50 & 60 & 75 & 100 & 50 & 100 & 75 & 100 & 100 & 75 & 84.4 & (75) \\
\hline \multirow[t]{3}{*}{$\begin{array}{l}\text { o) Liberación de } \\
\text { informe** }\end{array}$} & $\begin{array}{l}\text { 33. Fecha de } \\
\text { liberación }\end{array}$ & Sí & Sí & Sí & Sí & Sí & $5 / 5$ & Sí & Sí & Sí & Sí & No & Sí & Sí & Sí & $7 / 8$ & $12 / 13$ \\
\hline & 34. Hora de liberación & Sí & No & No & No & No & $1 / 5$ & Sí & Sí & No & No & No & Sí & Sí & Sí & $5 / 8$ & $6 / 13$ \\
\hline & $\%$ de cumplimiento & 100 & 50 & 50 & 50 & 50 & 60 & 100 & 100 & 50 & 50 & 0 & 100 & 100 & 100 & 75 & (69.2) \\
\hline \multirow[t]{3}{*}{$\begin{array}{l}\text { p) Numeración } \\
\text { de página }\end{array}$} & $\begin{array}{l}\text { 35. Número de } \\
\text { página }\end{array}$ & Sí & No & Sí & No & No & $2 / 5$ & Sí & Sí & No & Sí & Sí & Sí & Sí & Sí & $7 / 8$ & $9 / 13$ \\
\hline & $\begin{array}{l}\text { 36. Número total } \\
\text { de páginas }\end{array}$ & Sí & No & No & No & No & $1 / 5$ & Sí & Sí & No & Sí & Sí & Sí & Sí & No & $6 / 8$ & $7 / 13$ \\
\hline & $\%$ de cumplimiento & 100 & 0 & 50 & 0 & 0 & 30 & 100 & 100 & 0 & 100 & 100 & 100 & 100 & 50 & 81.3 & $(61.5)$ \\
\hline \multicolumn{2}{|c|}{$\%$ de cumplimiento global } & 48 & 46.9 & 48.4 & 51 & 29.1 & 44.7 & 60 & 65.6 & 50.5 & 58.4 & 61.3 & 68.1 & 72.2 & 71.5 & 63.5 & (56.2) \\
\hline
\end{tabular}

NA = no aplicable.

* Requisito evaluado sólo para un laboratorio.

** Se contemplaron los datos de impresión del resultado como el proceso final de liberación.

${ }^{* * *}$ Se evaluó el valor esperado de la presencia del virus como no detectado, ausente o negativo. 


\section{Identificación del paciente y del solicitante $(d, e)$}

Ningún laboratorio contuvo los siete elementos identificadores del paciente en conjunto. De los informes, 13/13 contuvieron el nombre del paciente y los mismos identificadores en todas las páginas del informe, 12/13 incluyeron un número de identificación único como folio o número de expediente, 9/13 incorporaron la edad expresada en años cumplidos, 7/13 insertaron registro del sexo, 2/13 introdujeron la fecha de nacimiento y 2/13 algún dato de ubicación del paciente como clínica o unidad a la que pertenece. El elemento menos registrado en los informes de laboratorios privados fue la ubicación del paciente (0/8), mientras que en los laboratorios públicos fueron la fecha de nacimiento y el sexo (0/5 y $1 / 5$, respectivamente).

La identificación del solicitante fue el segundo requisito con menor grado de cumplimiento general (11.5\%), 3/13 de los informes contuvieron el nombre del médico solicitante, mientras que el resto no presentaron identificación del solicitante, ni mención de que el paciente acudió por su propia voluntad a realizarse el examen.

\section{Información de la muestra primaria ( $f$ y g)}

De los informes sólo 3/13 contuvieron los tres elementos de este requisito; 5/13 incluyeron el tipo de muestra primaria y fecha de la toma de muestra, 4/13 tuvieron sólo alguno de los elementos y $1 / 13$ no contuvo ninguno de los elementos.

\section{Procedimiento de medición (h)}

Este requisito tuvo un cumplimiento general de 7.7\%; 3/13 informes contuvieron el nombre del kit de amplificación empleado en los blancos moleculares detectados. Ninguno de los informes analizados especificó criterios para determinar la positividad ni los valores de corte del ciclo umbral (Ct) de los genes amplificados. Dos informes mencionaron el nombre del kit de amplificación o la marca y modelo del equipo empleados, pero no mencionaron los blancos moleculares.

\section{Interpretación del resultado e intervalo de referencia $(i, j, k)$}

Doce de los informes expresan el resultado de manera que se comprende la presencia o ausencia del virus, mientras que un informe lo expresa como «POS», sin acotación que permita la interpretación clara del informe; a su vez, 10/13 presentan un intervalo de referencia expresado como la ausencia de amplificación o detección del virus. Los informes evaluados no contuvieron unidades de medición.

\section{Comentarios (I)}

El promedio de cumplimiento general de este requisito fue de 19.2\%; 4/14 mencionaron la utilidad del examen, de los cuales sólo el informe de un laboratorio privado contuvo información sobre las limitaciones de detección del ensayo.

\section{Identificación del responsable de revisión y autorización del informe (n)}

Este requisito tuvo un promedio de cumplimiento global de $75 \%$. Sin embargo, fue de $60 \%$ para los laboratorios del sector público. El nombre y la firma del responsable de laboratorio fueron los elementos contenidos en los 13 informes analizados, pero sólo 9/13 contuvieron la cédula profesional del responsable de emitir los resultados. De manera adicional, la identificación del responsable de la validación de los resultados o de una leyenda que confirmara que dicho proceso se ejecutó, sólo se detectó en 4/13 informes emitidos por laboratorios privados.

\section{Liberación del informe y numeración de página $(0, p)$}

Seis informes contuvieron la fecha y hora de liberación, emisión o impresión de resultados, mientras que 6/13 sólo contuvieron la fecha y $1 / 13$ no contuvo ninguno de los dos elementos. En cuanto a la numeración de página, 7/13 informes tuvieron ambos elementos, mientras que 2/13 sólo incluyeron el número de página, pero no el número total de páginas. 


\section{DISCUSIÓN}

Los requisitos de la ISO 15189:2012 junto con las recomendaciones de sociedades de profesionales de laboratorio permitieron establecer requisitos para el informe de resultados de la detección molecular de SARS-CoV-2. El diseño y formato del informe de resultados lo establece cada laboratorio; sin embargo, deberían cumplir los requisitos mínimos establecidos para garantizar que contiene la mínima información que refleje la calidad de los procesos postexamen y aportar valor a las decisiones clínicas. ${ }^{2}$ Los informes emitidos por 13 laboratorios que realizan este examen en México muestran variabilidad en el contenido, independientemente del sector económico al que pertenezcan. Esto hace difícil la investigación de errores de laboratorio en las etapas postexamen y postexamen clínica, lo cual disminuye la capacidad de detectar oportunidades para mejorar y garantizar la seguridad del paciente.

La comunicación efectiva es una de las acciones esenciales para la seguridad del paciente, ya que es el mecanismo que permite transmitir la información del paciente entre los diferentes actores de la atención sanitaria. ${ }^{13}$ En la medicina de laboratorio el informe de resultados es el principal medio de comunicación entre el laboratorio clínico y el médico, por lo que la deficiencia en la comunicación de resultados puede ocasionar una mala interpretación, mal uso o sobreuso de los exámenes de laboratorio, ${ }^{14}$ de tal manera que se afecta la calidad de la atención y seguridad del paciente al incrementar el riesgo de ocasionar errores de diagnóstico y/o tratamiento. Además, el uso inapropiado de las pruebas diagnósticas contribuye al desperdicio de recursos y disminuye la utilidad de la prueba cuando se usa en contextos clínicos diferentes a los especificados. ${ }^{15}$

En el diagnóstico genético y molecular la falta de conocimiento o experiencia en el tema por parte de los médicos puede originar errores de interpretación. ${ }^{16}$ Por lo que la mejora del contenido del informe es una estrategia que facilita el proceso de comunicación e interpretación de los resultados. ${ }^{17}$ Existe poca evidencia sobre la estandarización del contenido del informe de pruebas moleculares de enfermedades infecciosas y su impacto en la calidad de la atención y seguridad del paciente. Debido a esto es importante establecer un marco de referencia basado en las normas de calidad para lograr la comparabilidad entre laboratorios y asegurar la calidad de la etapa postexamen.

Los requisitos del informe que permiten la comprensión del resultado son: "uso de intervalo de referencia», «interpretación del informe» y «comentarios». La combinación de estos requisitos agregan valor al informe, lo que facilita la confirmación de un caso, la necesidad de realizar otra toma de muestra si el resultado es indeterminado y la capacidad de discernir entre falsos negativos cuando se sospeche de una baja carga viral o un tiempo de evolución prolongado de la enfermedad.12 Asimismo, la «identificación del laboratorio emisor» y de los «exámenes subcontratados» permiten la comunicación efectiva al favorecer la interconsulta cuando existan dudas sobre la interpretación de los resultados u otros aspectos, además de cubrir aspectos regulatorios como el uso de laboratorios aprobados por las autoridades sanitarias.

La «identificación correcta del paciente» como meta internacional para la seguridad del paciente involucra el uso de dos identificadores: nombre y fecha de nacimiento. ${ }^{18}$ Sólo dos de los informes incluyeron fecha de nacimiento como elemento de identificación y el resto utilizó la edad cumplida o no lo registró. La inclusión de otros elementos de identificación contribuye a un reconocimiento más certero del paciente y disminuye la probabilidad de confusiones, por ejemplo casos de pacientes con el mismo nombre y edad, o pacientes de diferente sexo con nombres similares.

Oportunidades destacables para mejorar el contenido del informe son el cumplimiento de los requisitos: «identificación del solicitante», «procedimiento de medición», «unidades del resultado» y «comentarios». Todos ellos impactan en el uso apropiado del laboratorio, que implica la selección del estudio correcto de acuerdo con la impresión diagnóstica del médico y del momento de la enfermedad. ${ }^{15}$ El uso apropiado se puede favorecer al establecer acciones de orientación a la población sobre el uso de la prueba diagnóstica cuando no se tiene una orden médica, por lo que se deberían monitorear los informes sin orden médica. El uso apropiado también se cumple al fomentar el aprendizaje del clínico durante la lectura del reporte. ${ }^{14}$ De este modo, el requisito «procedimiento de medición» permitirá conocer el fundamento; la 
incorporación de «unidades del resultado» permitirá comparar el desempeño de diferentes métodos y la variabilidad entre laboratorios, facilitando la mejora de los procedimientos diagnósticos. Esto último requerirá comparar los valores de los ciclos de umbral (Ct) de los controles con los puntos de corte definidos por el fabricante durante su validación. No obstante, se debe capacitar en el uso de los valores de Ct para no interpretarlos con estimaciones cuantitativas del virus, pero que sí pueden orientar a las decisiones clínicas. ${ }^{19,20}$ De manera adicional, el uso de comentarios interpretativos para describir los límites de detección del ensayo y las posibilidades de falsos positivos o negativos al analizar la combinación de blancos moleculares y los valores de Ct obtenidos por las muestras permitirán la correcta interpretación y uso apropiado.

La «identificación del examen»y la «información de la muestra primaria» también impactan en el uso apropiado del laboratorio. En la identificación del examen, el uso de la palabra COVID-19 debería evitarse, ya que el diagnóstico de COVID-19 no sólo depende de la presencia del virus. El ofertar un diagnóstico de COVID-19 haría necesario que el informe contuviera además de los resultados de la amplificación datos clínicos y epidemiológicos relevantes, lo cual está fuera de las responsabilidades del laboratorio. Por otra parte, el nombre del procedimiento del examen debería escribirse sin abreviaciones o siglas para evitar confusiones con el nombre de otros exámenes, por ejemplo, en español la proteína $C$ reactiva también se abrevia «PCR» y puede resultar confuso para profesionales poco familiarizados con los exámenes moleculares de laboratorio.

El requisito «información de la muestra primaria» favorece el proceso de tecnovigilancia, ya que la muestra tomada debe corresponder con la muestra validada por el fabricante del método, que se puede retroalimentar aún más si se incluye en los elementos de la identificación del examen las marcas de los kits empleados para la amplificación. Por último, la fecha y hora de la toma de muestra permitirá estimar el tiempo de respuesta del laboratorio al compararla con la fecha de liberación. El tiempo de respuesta es un indicador de calidad que se monitorea para evaluar el desempeño de la etapa postexamen al considerarse crítico para la acción oportuna cuando determinados exámenes están alterados. ${ }^{6}$

\section{CONCLUSIONES}

La estandarización del contenido del informe en la detección molecular de SARS-CoV-2 facilitará la interpretación del resultado y favorecerá el uso apropiado de este examen, al explicar la utilidad de la prueba y motivar el aprendizaje. Asimismo, permitirá la comparación entre distintas metodologías para mejorar los protocolos de diagnóstico. Se requiere realizar un consenso más detallado en el que participen sociedades de profesionales de laboratorio y médicos, así como evaluar el impacto del contenido estandarizado en la calidad de atención y seguridad del paciente.

\section{REFERENCIAS}

1. NMX-EC-15189-IMNC-2015 (ISO 15189:2012). Laboratorios Clínicos-Requisitos particulares de la calidad y competencia. Instituto Mexicano de Normalización y Certificación,A.C. 2015.

2. Lao EG, García AS, Figuerola MB, Moreno E, Paraire AH. Errors of clinical laboratory and its impact on patient safety. Open J Soc Sci. 2017; 5 (3):243-253. doi: 10.4236/jss.2017.53022.

3. Ching-Chow Y. Six sigma and total quality management. Rijeka, Croatia: InTech; 2010. Available in: http://cdn. intechopen.com/pdfs-wm/11581.pdf.

4. Hawkins R. Managing the pre- and post-analytical phases of the total testing process. Ann Lab Med. $2012 ; 32$ (1): 5-16. doi: 10.3343/alm.2012.32.1.5.

5. Sciacovelli L, Lippi G, Sumarac Z, West J, Garcia Del Pino Castro I, Furtado Vieira K et al. Quality indicators in laboratory medicine: the status of the progress of IFCC Working Group "Laboratory Errors and Patient Safety" project. Clin Chem Lab Med. 2017; 55 (3): 348-357. doi: 10.1515/cclm-2016-0929. PMID: 27988505.

6. Sciacovelli L, Aita A, Padoan A, Pelloso M, Antonelli G, Piva E et al. Performance criteria and quality indicators for the post-analytical phase. Clin Chem Lab Med. 2016; 54 (7): 1169-1176. doi: 10.1515/cclm-2015-0897. PMID: 26656613.

7. World Health Organization. Laboratory testing for coronavirus disease 2019 (COVID-19) in suspected human cases. Interim Guidance. Geneva: WHO; 2020. pp. 1-7. Available in: https://www.who.int/publicationsdetail/laboratory-testing-for-2019-novel-coronavirus-insuspected-human-cases-20200117.

8. Secretaría de Salud. Laboratorios con reconocimiento por parte del InDRE para realizar el diagnóstico de COVID 19 con fines de vigilancia epidemiológica. Secretaría de Salud; México: 2020.

9. Secretaría de Salud. NORMA Oficial Mexicana NOM-007SSA3-2011, Para la organización y funcionamiento de los laboratorios clínicos. México: Diario Oficial de la Federación;2012. 
10. Krleza JL, Honovic L, Tanaskovic JV, Podolar S, Rimac $\checkmark$, Jokic A. Post-analytical laboratory work: National recommendations from the working group for postanalytics on behalf of the Croatian society of medical biochemistry and laboratory medicine. Biochem Medica. 2019; 29 (2): 228-261. doi: 10.11613/BM.2019.020502.

11. Hong KH, Lee SW, Kim TS, Huh HJ, Lee J, Kim SY et al. Guidelines for laboratory diagnosis of coronavirus disease 2019 (COVID-19) in Korea. Ann Lab Med. 2020; 40 (5): 351360. doi: 10.3343/alm.2020.40.5.351.

12. Bohn MK, Mancini N, Loh TP, Wang CB, Grimmler M, Gramegna $\mathrm{M}$ et al. IFCC Interim guidelines on molecular testing of SARS-CoV-2 infection. Clin Chem Lab Med. 2020; 58 (12): 1993-2000. doi: 10.1515/cclm-2020-1412.

13. World Health Organization. Better knowledge for safer care: human factors in patient safety. Geneva: World Health Organization; 2009. p. 55. Available in: http://www. who.int/patientsafety/research/methods_measures/ human_factors/human_factors_review.pdf.

14. Scheuner MT, Hilborne L, Brown J, Lubin IM. A report template for molecular genetic tests designed to improve communication between the clinician and laboratory. Genet Test Mol Biomarkers. 2012; 16 (7): 761-769. doi: 10.1089/ gtmb.2011.0328.
15. Cappelletti P. Appropriateness of diagnostics tests. Int J Lab Hematol. 2016; 38: 91-99. doi: 10.1117/ijlh.12502.

16. Suther S, Goodson P. Barriers to the provision of genetic services by primary care physicians: A systematic review of the literature. Genet Med. 2003; 5 (2): 70-76. doi: 10.1097/01. CIM.0000055201.16487.61.

17. Scheuner MT, Edelen MO, Hilborne LH, Lubin IM. Effective communication of molecular genetic test results to primary care providers. Genet Med. 2013; 15 (6): 444-449. doi: 10.1038/gim.2012.151.

18. Consejo de Salubridad General. ACUERDO Por el que se declara la obligatoriedad de la implementación, para todos los Integrantes del Sistema Nacional de Salud, del documento denominado Acciones Esenciales Para La Seguridad Del Paciente. México: Diario Oficial de la Federación; 2017. Disponible en: http://www.dof.gob.mx/ nota_detalle.php?codigo=5496728\&fecha=08\%2F09\% 2F2017.

19. Han MS, Byun JH, Cho Y, Rim JH. RT-PCR for SARS-CoV-2: quantitative versus qualitative. Lancet Infect Dis. 2021; 21 (2): 165. doi: 10.1016/S1473-3099(20)30424-2.

20. Tom MR, Mina MJ. To interpret the SARS-CoV-2 test, consider the cycle threshold value. Clin Infect Dis. 2020; 71 (16): 2252-2254. doi: 10.1093/cid/ciaa619.

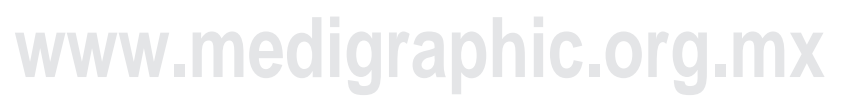

